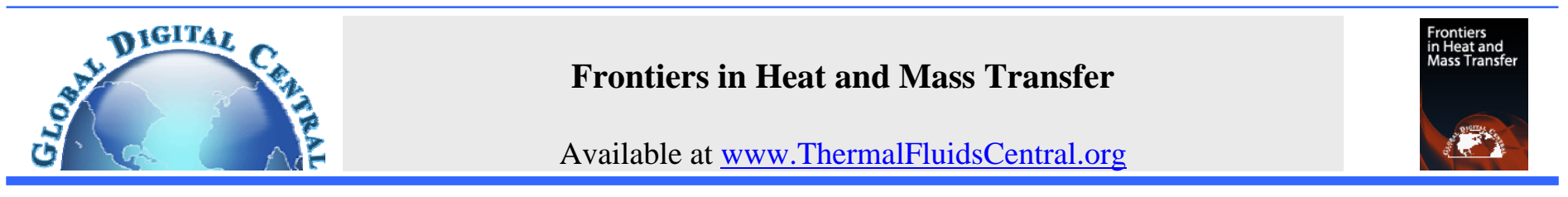

\title{
MICROPOLAR FLUID FLOW OVER A NONLINEAR STRETCHING CONVECTIVELY HEATED VERTICAL SURFACE IN THE PRESENCE OF CATTANEO-CHRISTOV HEAT FLUX AND VISCOUS DISSIPATION
}

\author{
Machireddy Gnaneswara Reddy ${ }^{\mathrm{a}, ~ *}$, Gorla Rama Subba Reddy, \\ ${ }^{a}$ Department of Mathematics, Acharya Nagarjuna University Campus, Ongole, 523001, India, \\ ${ }^{b}$ Department of Mechanical and Civil Engineering, Purdue University Northwest, Westville, IN, 4639, USA
}

\begin{abstract}
The objective of the present communication is to study the problem of micropolar fluid flow with temperature dependent thermal conductivity over a nonlinear stretching convective vertical surface in the presence of Lorentz force and viscous dissipation. Due to the nature of heat transfer in the flow past vertical surface, Cattaneo-Christov heat flux model and Joule heating effects are properly accommodated in the energy equation. The governing partial differential equations for the flow and heat transfer are converted into a set of ordinary differential equations by employing the acceptable similarity transformations. Runge-Kutta and Newton's methods are utilized to resolve the altered governing nonlinear equations. Obtained numerical results are compared with the available literature and found to be an excellent agreement. The impacts of dimensionless governing flow pertinent parameters on velocity, micropolar velocity and temperature profiles are presented graphically and analyzed in detail. Further, the variations of skin friction coefficient and local Nusselt number are displayed for the sundry flow parameters. It is found that fluid temperature profile declines for larger thermal relaxation parameter. Both temperature and thermal boundary layer thickness decreases for enhancing values of Prandtl number.
\end{abstract}

Keywords: Magnetohydrodynamics, micropolar fluid, heat transfer, convective boundary condition, Cattaneo-Christov heat flux.

\section{INTRODUCTION}

The concept of micropolar fluids has come into prominence because of the conventional Newtonian fluids cannot accurately represent the features of fluid flow in various engineering applications namely polymeric fluids, paints and colloidal solutions, biology etc. A class of fluids has also considering its microstructure is known as micropolar fluids. Micropolar fluids are physically represent fluids in which the deformation of the particles omitted in the fluids and consisting of a suspension of rigid, spherical particles in a viscous medium. The micropolar fluids model was introduced by Eringen (1966) and covering in both theory and applications than the classical one. An analysis of boundary-layer theory for a micropolar fluid has extended by Peddieson and McNitt (1970). Heat transfer flow in a polar fluid towards a nonisothermal stretching surface with suction and blowing have been numerically investigated by Hassanien and Gorla (1990). For the formulation of mathematic model they are utilizing the Erigen theory of micropolar fluids. Rama Subba Reddy (1995) have investigated the problem of mixed convection boundary layer on unsteady micropolar flow over a vertical plate and reveals that the friction factor and rate of heat transfer enhances to the improve of buoyancy force. Hady (1996) studied an analytical solution of heat transfer in micropolar fluid over a non-isothermal permeable stretching sheet. The flow characteristics of micropolar fluid in moving wedge and flat plate have been analyzed by Ishak et al. (2006). By the same authors (2008) have presented to the heat transfer analysis on micropolar fluids in a stretching surface. Mixed convection flow of a micropolar fluid towards a non-linear stretching surface investigated Hayat et al. (2008). The series solution retained by imposing HAM to the transformed coupled non-linear ordinary differential equations. The problem of micropolar fluid filled a porous channel was discussed by Sajid et al. (2009).

The interaction of MHD (magnetohydrodynamic) has more significant applications in the fields of aerospace engineering, medicine and geo and astrophysics. Several equipments including turbulent pumps, bearings, MHD generators and boundary layer control flow are influenced due to the interaction between the electrically conducting liquid and magnetic field. Ashraf and Batool (2013) studied the magnetohydrodynamic flow and heat transfer behavior of a micropolar fluid past a stretchable disk. It is predict that the fluid flow of magnetic field strengthen the skin friction coefficient. Mahmoud and Waheed (2012) studied heat transfer flow in micropolar fluid through a stretching sheet in the presence of magnetic field. Heat generation effect on steady hydromagnetic flow of micropolar fluid over a moving surface was presented by Gnaneswara Reddy (2013). Viscous dissipation effect for the convection flow of a micropolar fluid towards a stretching surface is examined by El-Aziz (2013). Gnaneswara Reddy and Venugopal Reddy (2015) have reported the interaction of Joule heating on magnetohydrodynamic peristaltic transport of a Nanofluid. The interaction of heat transfer and hydromagnetic on a rotating micropolar fluid was recently analyzed by Mehmood et al. (2016). Gnaneswarara Reddy $(2014,2014)$ have reported the effect of viscous dissipation on steady MHD flow over stretched surface. Alam et al. (2016) have discussed the analysis of temperature dependent thermal conductivity on magnetohydrodynamic flow with distinct nanoparticles. The peristaltic transport of Jeffrey nanofluid over an asymmetric channel with magnetic field investigated recently Gnaneswara Reddy and Makinde (2016). Sandeep and Gnaneswara Reddy (2017) have recently analyzed the impact of heat transfer on MHD thermal radiative flow in two distinct geometries.

*Corresponding author.Email: mgrmaths@gmail.com 
The classical Fourier's (1822) heat conduction is amongst the best utilized models in classical physics and which is used for the description of heat transfer transport mechanism in various associated situations. The one of major limitation for parabolic energy equation for temperature is that unique disturbance and simultaneously it dispute the principle of causality throughout whole medium. Fourier's law of heat conduction is modified in context of thermal relaxation by Cattaneo (1948). Hyperbolic type energy equation exists in presence of Cattaneo's expression. Christov (2009) improved the heat conduction analysis of Cattaneo (1948) by introducing thermal relaxation time along with Oldroyd's upper-convicted derivative, in order to attain the material invariance of the model. Cattaneo-Cheristov heat flux model is the modified Fourier's form which gives thermal relaxation time. CattaneoChristov model with influence of thermal convection was studied by Straughan (2010). Uniqueness of Cattaneo-Christov heat flux model for flow of incompressible fluids has been analyzed Tibullo and Zampoli (2011). Han et al. (2014) reported the Cattaneo-Christov heat flux model on boundary layer flow of a Maxwell fluid. Mustafa (2015) investigated the interaction of Cattaneo-Christov heat flux model for rotating flow of a Maxwell fluid with heat transfer. The problem of Cattaneo-Christov heat flux model on Viscoelastic Flow over an exponentially stretching surface is recently discussed khan et al. (2015). Impact of temperature dependent thermal conductivity fluid and Cattaneo-Christov heat flux flow of over a surface is examined Hayat et al. (2016).

Owing the above-mentioned investigations, the main goal of the present study is to investigate the impact of temperature dependent thermal conductivity and MHD convection flow of micropolar fluid towards nonlinear stretched surface. The convective condition is also considered in the energy boundary conditions. The present problem is the extension work of very recently published work of Waqas et al. (2016) to addressed the temperature dependent thermal conductivity and Cattaneo-Christov heat flux in energy equation. The dimensionless nonlinear partial differential equations are transformed into ordinary differential equations by utilizing suitable similarity transformations and are solved numerically. A detailed parametric study is presented graphically to explore the interaction of various controlling flow physical parameters on velocity, micro-rotation and temperature distribution. Also the friction factor and local Nusselt number are tabulated and analyzed.

\section{MATHEMATICAL MODELING}

Let us consider a steady two-dimensional electrically conducting free convection flow of a viscous and an incompressible micropolar fluid induced by a nonlinear stretching surface. The physical model of the present flow problem is shown in Fig.1. It is also further considered a general power-law surface velocity distribution $u_{w}=a x^{n}$ with $a>0$. There is a non- uniform applied magnetic field of strength $B(x)=B_{0} x^{\frac{n-1}{2}}$ in the direction of $y$-axis which is normal to $X$ - axis. The Cattaneo-Christov heat flux model is considered in the heat transfer analysis. It is assumed that the energy at the place is passively adjusted through heated fluid of temperature $T_{f}$ below the surface of the wall. Let $T_{\infty}$ be the temperature outside the thermal boundary layer. The thermal conductivity of fluid is not constant is retained. Viscous dissipation, convective condition and Joule heating effects are also invoked. It is also assumed that the electric field is absent whereas the induced magnetic field is neglected by assuming low magnetic Reynolds number. Under the above the assumptions and boundary layer approximation, the governing equation of motion and energy are given by

$\frac{\partial u}{\partial x}+\frac{\partial v}{\partial y}=0$

$$
\begin{aligned}
& u \frac{\partial u}{\partial x}+v \frac{\partial u}{\partial y}=\left(v+\frac{\kappa}{\rho}\right) \frac{\partial^{2} u}{\partial y^{2}}+\frac{\kappa}{\rho} \frac{\partial N}{\partial y}+g \beta\left(T-T_{\infty}\right)-\frac{\sigma B^{2}(x)}{\rho} u, \text { (2) } \\
& u \frac{\partial N}{\partial x}+v \frac{\partial N}{\partial y}=\frac{\gamma^{*}}{\rho j} \frac{\partial^{2} N}{\partial y^{2}}-\frac{\kappa}{\rho j}\left(2 N+\frac{\partial u}{\partial y}\right), \\
& u \frac{\partial T}{\partial x}+v \frac{\partial T}{\partial y}+\lambda_{1}\left(\begin{array}{l}
\left.u \frac{\partial u}{\partial x} \frac{\partial T}{\partial x}+v \frac{\partial v}{\partial y} \frac{\partial T}{\partial y}+u \frac{\partial v}{\partial x} \frac{\partial T}{\partial y}+v \frac{\partial u}{\partial y} \frac{\partial T}{\partial x}\right) \\
+2 u v \frac{\partial^{2} T}{\partial x \partial y}+u^{2} \frac{\partial^{2} T}{\partial x^{2}}+v^{2} \frac{\partial^{2} T}{\partial y^{2}}
\end{array}\right) \\
& =\frac{1}{\rho c_{p}} \frac{\partial}{\partial y}\left(k(T) \frac{\partial T}{\partial y}\right) \frac{\partial^{2} T}{\partial y^{2}}+\frac{1}{c_{p}}\left(v+\frac{\kappa}{\rho}\right)\left(\frac{\partial u}{\partial y}\right)^{2}+\frac{\sigma B^{2}(x)}{\rho c_{p}} u^{2},
\end{aligned}
$$

and the relevant boundary conditions for the present model are

$$
\begin{aligned}
& u=u_{w}=a x^{n}, v=0, N=-m_{0} \frac{\partial u}{\partial y},-k_{1} \frac{\partial T}{\partial y}=h_{f}\left(T_{f}-T\right) \text { at } y=0, \\
& u \rightarrow 0, N \rightarrow 0, T \rightarrow T_{\infty} \text { as } y \rightarrow \infty .
\end{aligned}
$$

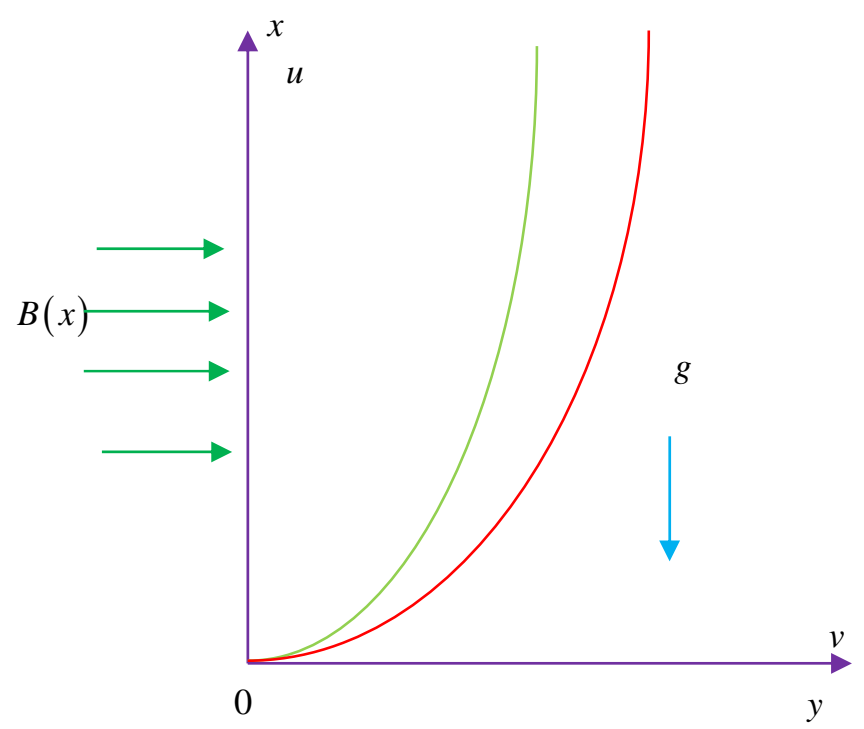

Fig. 1 Schematic diagram of the flow problem.

where the components $u$ and $v$ are the velocities along $x$-and $y$ axis respectively, $k$ is the vortex viscosity, $\rho$ is the fluid density, $\mu$ is the dynamic viscosity, $g$ is the gravitational acceleration, $\beta$ is the thermal expansion coefficient, $v$ is the kinematic viscosity, $\gamma^{*}=\left(\mu+\frac{k}{2}\right) j$ is the spin gradient viscosity,$\alpha=\frac{k_{1}}{\rho c_{p}}$ is the thermal diffusivity, $N$ is the micro rotation velocity, $j=v / a$ is the micro inertia, $k(T)$ is the variable thermal conductivity, $T_{f}$ is the convective fluid temperature, $c_{p}$ is the specific heat at constant pressure, $m_{0}$ is the boundary parameter and $h_{f}$ is the convective heat transfer coefficient .

It is assumed that the thermal conductivity $k(T)$ to vary linearly with temperature and taken of the form (Hayat et al. (2016))

$$
k(T)=k_{\infty}(1+\varepsilon \theta)
$$


where $k_{\infty}$ is the thermal conductivity of the ambient fluid and $\varepsilon$ is the small scalar parameter.

Define the following similarity transformations and variable quantities:

$$
\begin{aligned}
& \psi=\sqrt{\frac{2}{n+1} v a x^{n+1}} f(\eta), \eta=\sqrt{\frac{a(n+1)}{2 v} x^{\frac{n-1}{2}} y, K=\frac{k}{\mu},} \\
& N=a x^{n} \sqrt{\frac{a(n+1)}{2 v}} x^{\frac{n-1}{2}} g(\eta), \theta(\eta)=\frac{T-T_{\infty}}{T_{w}-T_{\infty}}, u=c x^{n} f^{\prime}(\eta), \\
& v=\sqrt{\frac{c v(n+1)}{2} x^{\frac{n-1}{2}}\left[f(\eta)+\frac{n-1}{n+1} \eta f^{\prime}(\eta)\right], \lambda=\frac{G r_{x}}{\operatorname{Re}_{x}^{2}},} \\
& G r_{x}=\frac{g \beta\left(T_{w}-T_{\infty}\right) x^{3}}{v^{2}}, \operatorname{Re}_{x}=\frac{u_{w} x}{v}, M^{2}=\frac{\sigma B^{2}(x)}{a \rho x^{n-1}}, \\
& \gamma=\lambda_{1} a x^{n-1}, \operatorname{Pr}=\frac{v}{\alpha}, E c=\frac{u_{w}^{2}}{c_{p}\left(T_{w}-T_{\infty}\right)}, B i=\frac{h_{f}}{k_{1}} \sqrt{\frac{v}{a}} x^{-\left(\frac{n-1}{2}\right)}
\end{aligned}
$$

It is obvious that the continuity equation (1) is automatically satisfied. The remaining governing flow equations (2) - (4) and corresponding boundary conditions (5), which are reduced to the following dimensionless, coupled ordinary differential equations

$$
\begin{aligned}
& (1+K) f^{\prime \prime \prime}+f f^{\prime \prime}-\frac{2 n}{n+1} f^{\prime 2}+K g^{\prime}+\frac{2}{n+1} \lambda \theta-\frac{2}{n+1} \\
& \left(1+\frac{K}{2}\right) g^{\prime \prime}+f g^{\prime}-\frac{3 n-1}{n+1} f^{\prime} g-\frac{2 K}{n+1}\left(2 g+f^{\prime \prime}\right)=0, \\
& (1+\varepsilon \theta) \theta^{\prime \prime}+\varepsilon \theta^{\prime 2}+\operatorname{Pr} \gamma\left(\frac{n-3}{2} f f^{\prime} \theta^{\prime}-\frac{n+1}{2} f^{2} \theta^{\prime \prime}\right) \\
& +\operatorname{Pr} \theta\left(\gamma f f^{\prime \prime}-\frac{2 n}{n+1} \gamma f^{\prime 2}-\frac{2}{n+1} f^{\prime}\right)+\operatorname{Pr} f \theta^{\prime} \\
& +\operatorname{Pr} E c(1+K) f^{\prime 2}+\operatorname{Pr} E c M^{2} f^{\prime 2}=0,
\end{aligned}
$$

and the reduced conditions are:

$$
\begin{aligned}
& f(0)=0, f^{\prime}(0)=1, g(0)=-m_{0} f^{\prime \prime}(0), \theta^{\prime}(0)=-B i(1-\theta(0)), \\
& f^{\prime}(\eta) \rightarrow 0, g(\eta) \rightarrow 0, \theta(\eta) \rightarrow 0 \text { as } \eta \rightarrow \infty
\end{aligned}
$$

where primes indicates differentiation with respect to $\eta, K$ the micro polar parameter , $\lambda$ the mixed convection parameter , $G r_{x}$ the thermal buoyancy parameter, $\operatorname{Re}_{x}$ the local Reynolds number, $M$ the Hartman number, $\operatorname{Pr}$ the Prandtl number, $\gamma$ the thermal relaxation parameter, $E c$ the Eckert number and $B i$ the Biot number.

For physical quantities of interest, the local friction factor coefficient $C_{f}$ with surface shear stress $\tau_{w}$ and local Nusselt number $N u_{x}$ with surface heat flux $q_{w}$ are given by

$$
\begin{aligned}
& C_{f}=\frac{2 \tau_{w}}{\rho u_{w}^{2}} \\
& N u_{x}=\frac{x q_{w}}{k_{1}\left(T_{f}-T_{\infty}\right)}
\end{aligned}
$$

where the quantities $\tau_{w}$ and $q_{w}$ are given by

$$
\begin{aligned}
& \tau_{w}=\left((\mu+k) \frac{\partial u}{\partial y}+k N\right)_{y=0} \\
& q_{w}=-k_{1}\left(\frac{\partial T}{\partial y}\right)_{y=0}
\end{aligned}
$$

By incorporating the similarity transformations and quantities in to Equations (12) and (13), the reduced dimensionless skin friction coefficient and local Nusselt number are given by

$$
\begin{aligned}
& C_{f} \operatorname{Re}_{x}^{1 / 2}=\sqrt{\frac{n+1}{2}}\left(1+\left(1-m_{0}\right) K\right) f^{\prime \prime}(0) \\
& N u_{x} \operatorname{Re}_{x}^{-1 / 2}=-\sqrt{\frac{n+1}{2}} \theta^{\prime}(0)
\end{aligned}
$$

where $\operatorname{Re}_{x}=u_{w} x / v$ is the local Reynolds number.

\section{NUMERICAL SOLUTION}

The resultant differential equations (8) - (10) with the boundary restrictions (11) are not possible to find the exact solutions due to the equations are highly nonlinear and coupled. Hence there equations are resolved numerically with Runge-Kutta based shooting method. Initially, the set of nonlinear ordinary differential equations (8), (9) and (10) converted to first order ordinary differential equations, by using the following procedure:

$$
\begin{aligned}
& f=y_{1}, f^{\prime}=y_{2}, f^{\prime \prime}=y_{3}, \\
& f^{\prime \prime \prime}=\frac{1}{1+K}\left[-y_{1} y_{3}+\frac{2 n}{n+1} y_{2}^{2}-k y_{5}-\frac{2}{n+1} \lambda y_{6}+\frac{2}{n+1} M^{2} y_{2}\right] \\
& g=y_{4}, g^{\prime}=y_{5}, \\
& g^{\prime \prime}=\frac{1}{\left(1+\frac{k}{2}\right)}\left[-y_{1} y_{5}+\frac{3 n-1}{n+1} y_{2} y_{4}+\frac{2 K}{n+1}\left(2 y_{4}+y_{3}\right)\right] \\
& \theta=y_{6}, \theta^{\prime}=y_{7},
\end{aligned}
$$

$$
\theta^{\prime \prime}=\frac{1}{\left(\begin{array}{l}
1+\varepsilon y_{6} \\
-\operatorname{Pr} \gamma\left(\frac{n+1}{2}\right) y_{1}^{2}
\end{array}\right)}\left[\begin{array}{l}
-\operatorname{Pr}\left(\gamma y_{1} y_{3}-\frac{2 n}{n+1} \gamma y_{2}^{2}-\frac{2}{n+1} y_{2}\right) \\
-\varepsilon y_{7}^{2}-\operatorname{Pr} \gamma\left(\frac{n-3}{2} y_{1} y_{2} y_{7}\right) \\
-\operatorname{Pr} E c M^{2} y_{2}^{2}-\operatorname{Pr} y_{1} y_{7} \\
-\operatorname{Pr} E c(1+K) y_{3}^{2}
\end{array}\right]
$$

with the corresponding boundary conditions

$$
\begin{aligned}
& y_{1}=0, y_{2}=1, y_{4}=-m_{0} y_{2}, y_{7}=-B i\left(1-y_{6}\right) \text { at } \eta=0 \\
& y_{2}=0, y_{4}=0, y_{6}=0 \quad \text { as } \eta \rightarrow \infty
\end{aligned}
$$

First guess the values of undefined initial conditions $y_{3}(0), y_{5}(0)$ and $y_{7}(0)$ which are involved in equations (18) - (20). Once all initial conditions are found then we solve the equations (18)-(20) are integrated by using Runge-Kutta fourth order method with the successive iterative step length is 0.01 . In order to validates the accuracy of the present solutions with those solutions of Waqas et al. (2016) and Cortell (2007) and found excellent agreement with those solutions.

\section{RESULTS AND DISCUSSION}

The impact of various pertinent parameters such as magnetic field parameter $M$, material parameter $K$, mixed convection parameter $\lambda$, boundary parameter $m_{0}$, thermal relaxation parameter $\gamma$, variable thermal conductivity parameter $\varepsilon$, of Prandtl number $\operatorname{Pr}$, Eckert number $E c$ and Biot number $B i$ on the velocity, micropolar velocity, 


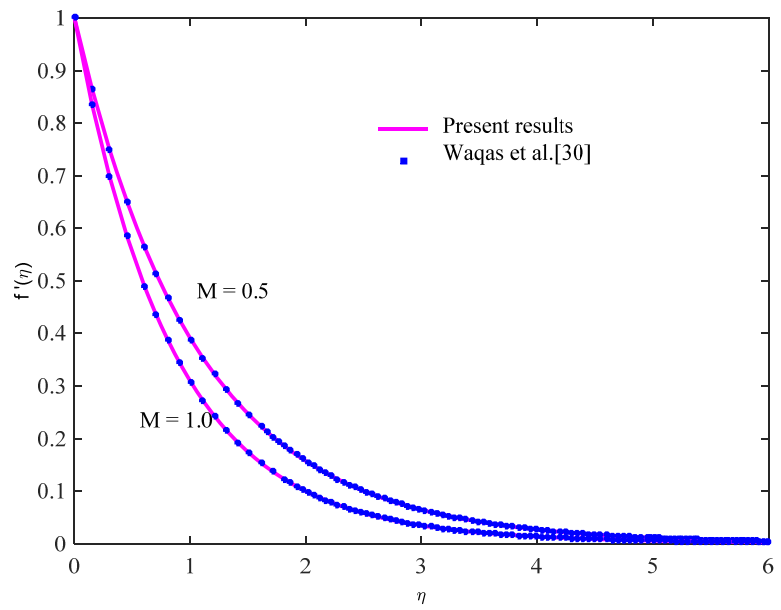

Fig. 2 Comparison of $M$ on velocity

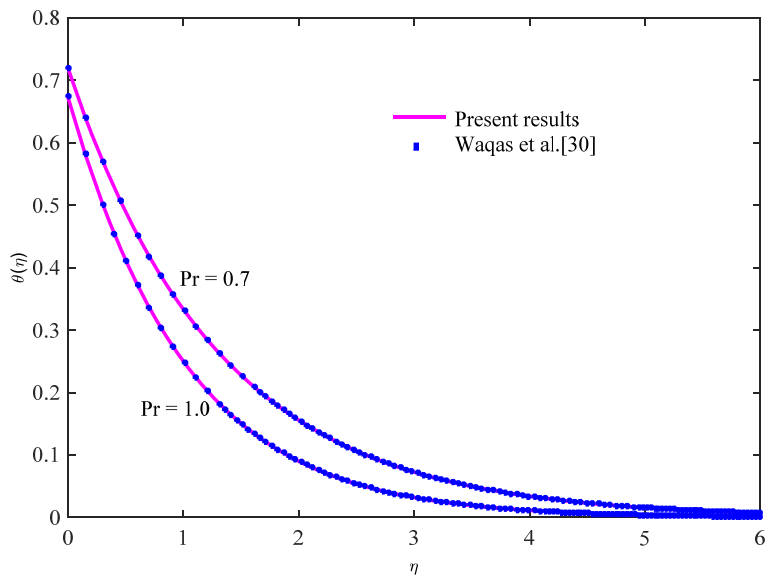

Fig. 3 Comparison of $M$ on temperature

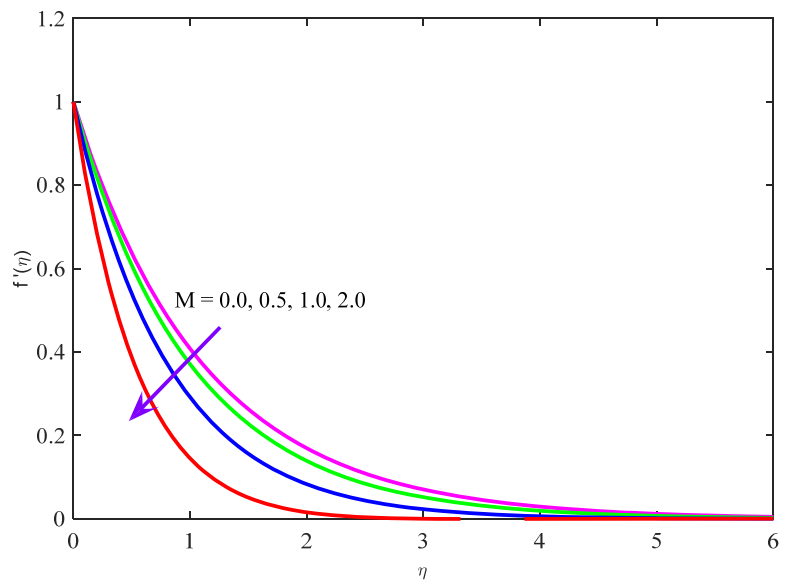

Fig. 4 Influence of $M$ on $f^{\prime}(\eta)$

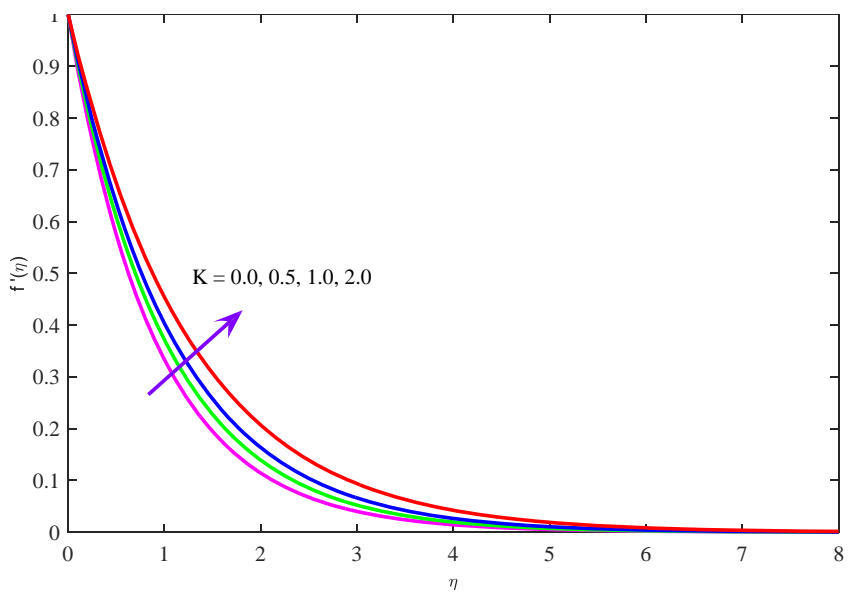

Fig. 5 Influence of $K$ on $f^{\prime}(\eta)$

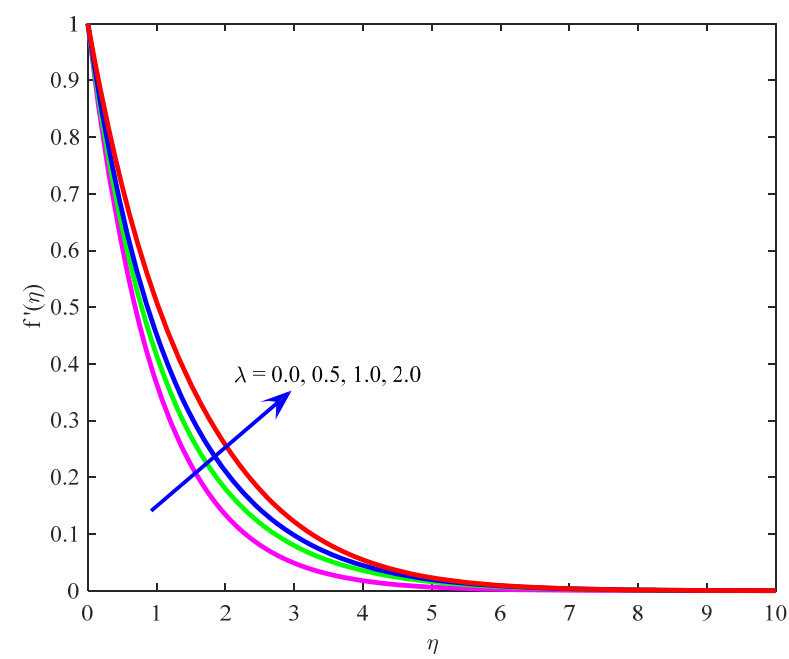

Fig. 6 Influence of $\lambda$ on $f^{\prime}(\eta)$

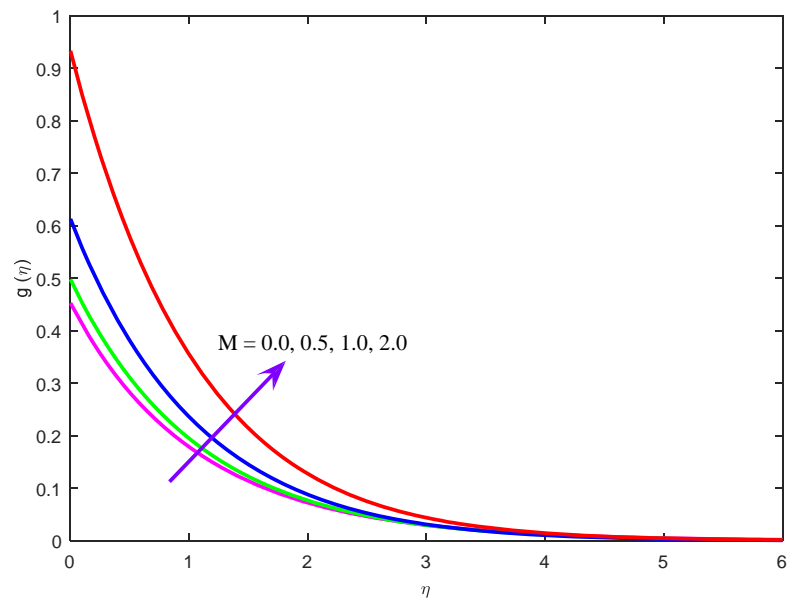

Fig. 7 Influence of $M$ on $g(\eta)$ 


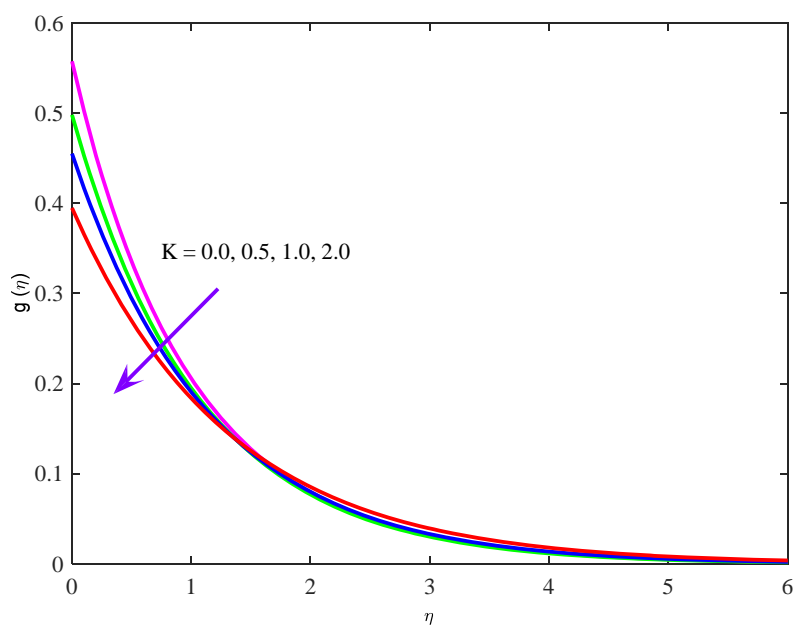

Fig. 8 Influence of $K$ on $g(\eta)$

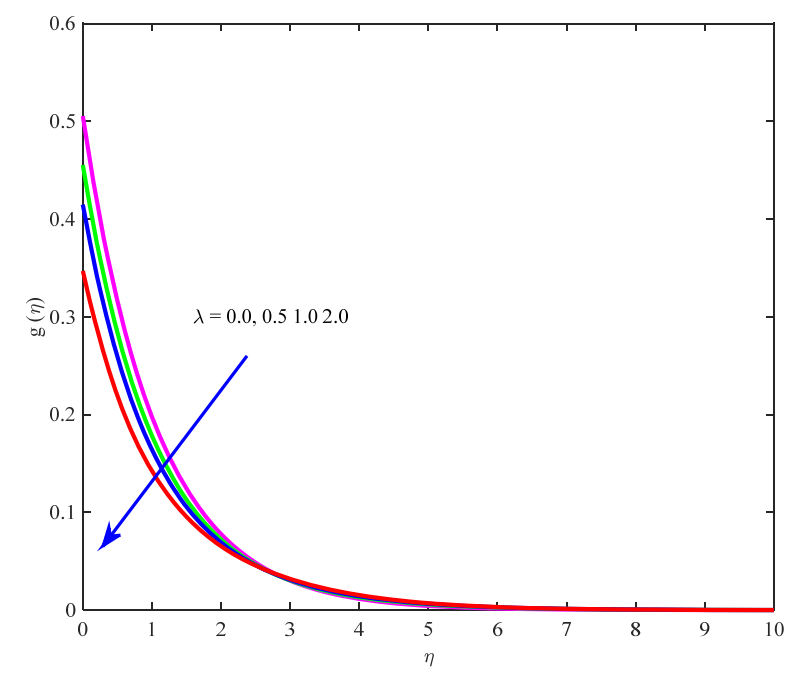

Fig. 9 Influence of $\lambda$ on $g(\eta)$

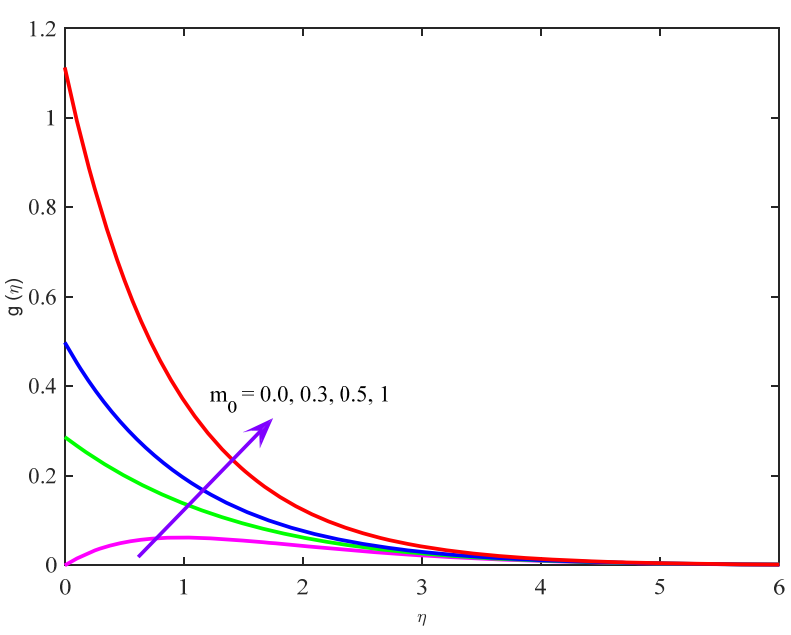

Fig. 10 Influence of $m_{0}$ on $g(\eta)$

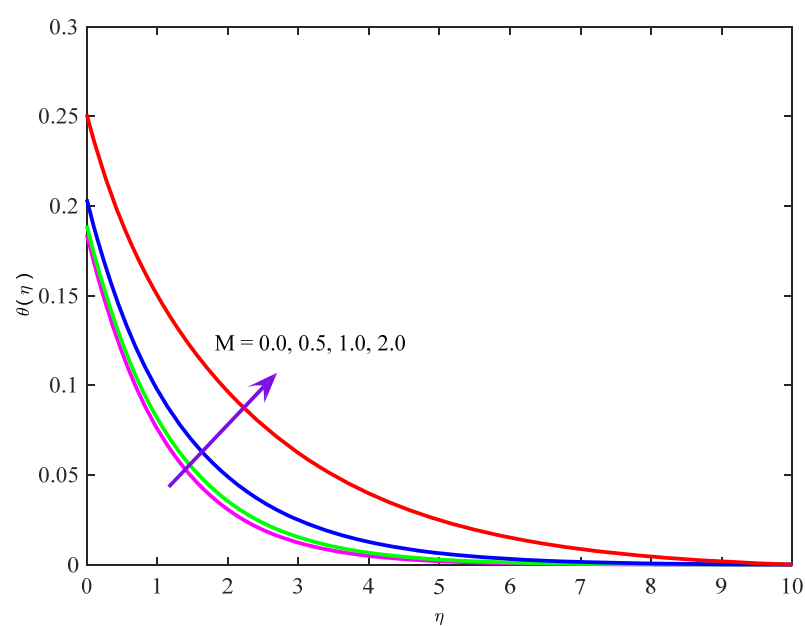

Fig. 11 Influence of $M$ on $\theta(\eta)$

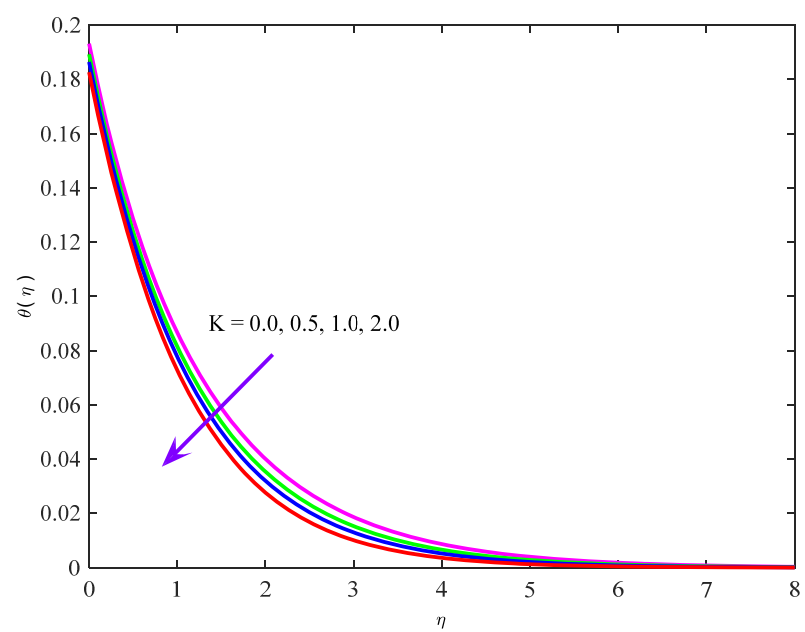

Fig. 12 Influence of $K$ on $\theta(\eta)$

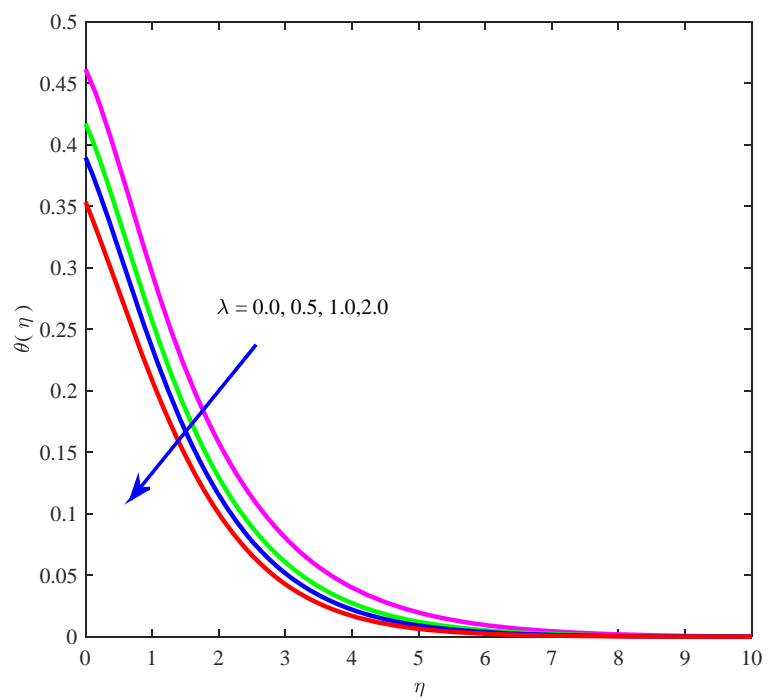

Fig. 13 Influence of $\lambda$ on $\theta(\eta)$ 


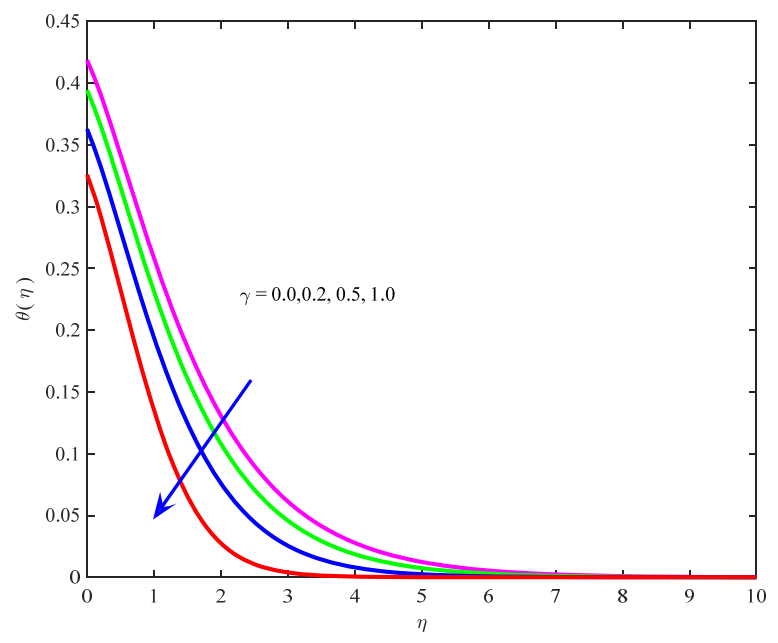

Fig. 14 Influence of $\gamma$ on $\theta(\eta)$

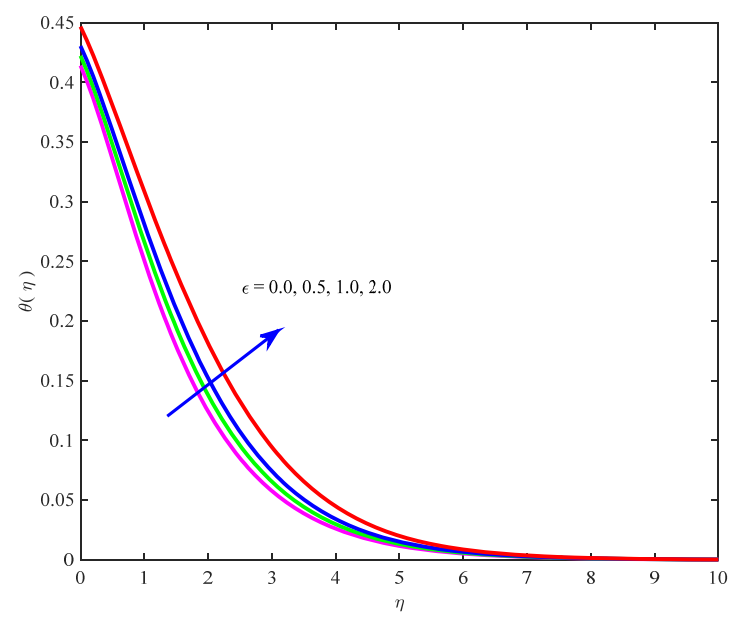

Fig. 15 Influence of $\varepsilon$ on $\theta(\eta)$

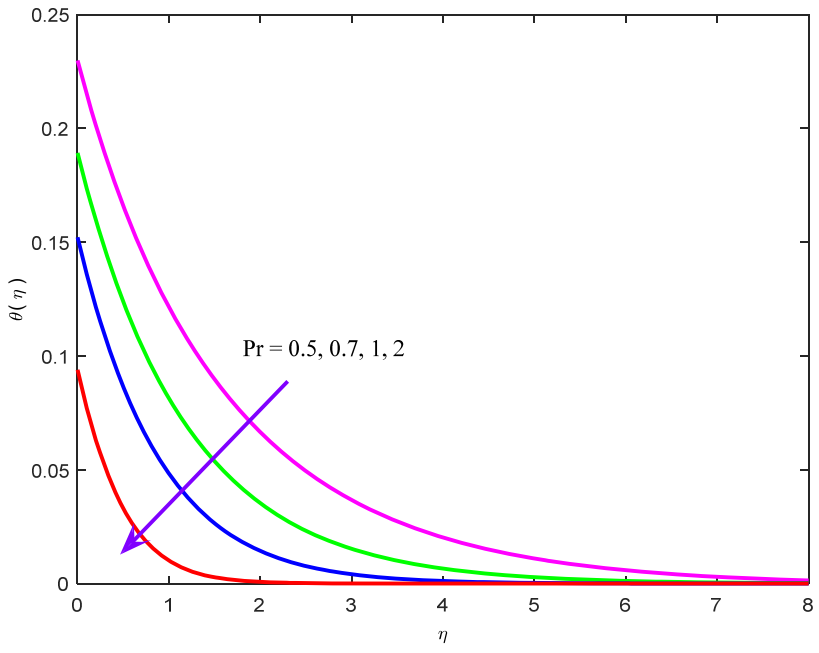

Fig. 16 Influence of $\operatorname{Pr}$ on $\theta(\eta)$

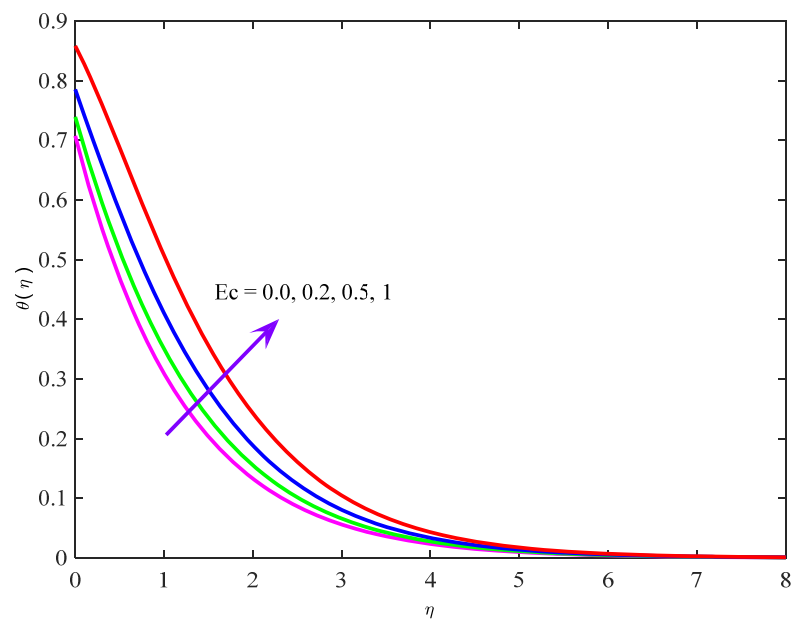

Fig. 17 Influence of $E c$ on $\theta(\eta)$

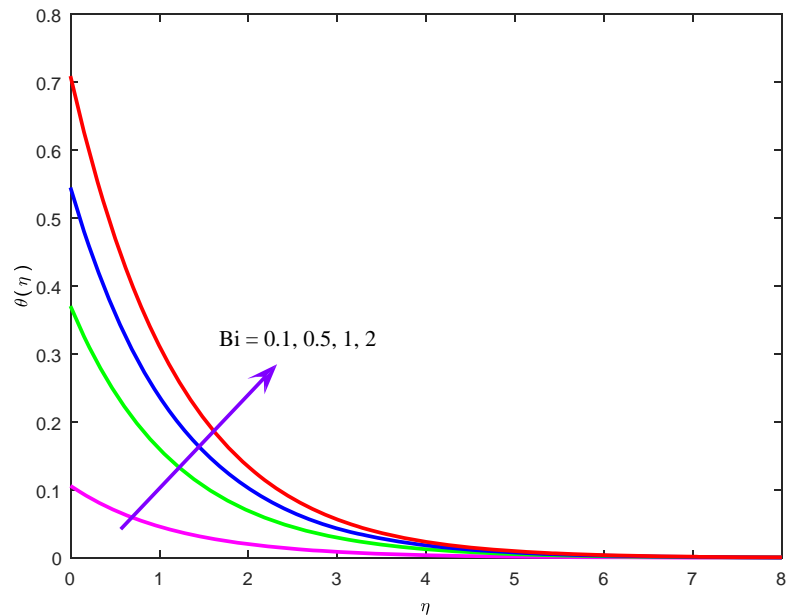

Fig. 18 Influence of $\mathrm{Bi}$ on $\theta(\eta)$

and temperature distributions have been prepared. For numerical computations, we have kept fixed values of the dimensionless numbers for this study: $K=0.5, n=1.2, \lambda=0.2, M=0.5, \varepsilon=0.2$, $\operatorname{Pr}=0.7, \gamma=0.2, m_{0}=0.5, B i=0.2 E c=0.01$.

Fig. 2 reveals that the comparison velocity distribution for two values of magnetic field parameter ( $M=0.5$ and $M=1.0$ ). It is evident from this figure that our numerical results are in good agreement with the recent published work by Waqas et al. (2016). The comparison dimensionless temperature distribution for Prandtl number is also presented in Fig. 3. It can be showed that our results are in nice agreement with published work done by Waqas et al. (2016)

Fig.4 displays the behavior of magnetic field parameter $M$ on velocity distribution. It is found that for higher values of magnetic field parameter decrease the magnitude of velocity distribution and reduced the boundary layer thickness. This is due to an increase in magnetic field on the fluid flow produces a resistance fore and which is called the Lorentz force. Further, we conclude this figure that hydro magnetic case is weaker than in comparison to the hydrodynamic case. It can be seen that transverse magnetic field resists the flow phenomena. Influence of micropolar parameter $K$ on velocity distribution is elucidated in Fig.5. It is observed that velocity distribution increased for larger values micropolar parameter. Because larger values of micropolar parameter 
which corresponds to the low viscosity and enhance the velocity. This behavior coincides with the results of Gnaneswara Reddy [2013]. Fig.6 plots the effect of mixed convection parameter on velocity distribution. The velocity boosts with increasing values of mixed convection parameter $\lambda$. Because increase in mixed convection parameter to enhance the buoyancy force and this is evident in the progressive increase in the flow velocity.

Fig. 7 illustrates the influence of magnetic field parameter $M$ on micro-rotation velocity profiles. From this figure we can observed that the micropolar velocity distribution is rises with an ascending values of $M$. The behavior of material parameter $K$ angular velocity is plotted in Fig.8. It can be found that initially angular velocity reduces by increasing of $K$ while the opposite behavior to the free stream velocity. Fig.9 illustrates the influence of mixed convection parameter on microrotation velocity distribution. The angular velocity is decreases there is rise in the buoyancy parameter. The effect of boundary parameter $m_{0}$ on the angular velocity is portrays in Fig. 10. The angular velocity is enhanced for larger boundary parameter $m_{0}$. The micro-rotation velocity is vanished for $m_{0}=0$.

The impact of magnetic field parameter on the temperature distribution is prepared in Fig. 11. The temperature distribution is enhances with the larger values of magnetic field parameter. Here hydrodynamic case $(M=0)$ is weaker in comparison to the hydro magnetic case. It can be noticed that the thickness of thermal boundary thickness increase with an increase in $M$. The behavior of magnetic field parameter on micro polar velocity and temperature is similar trend but the opposite for the velocity. The behavior of micropolar parameter $K$ on temperature distribution is sketched in Fig.12. Temperature distribution is diminishes with the larger values of micropolar parameter. The velocity increases while the temperature is having the reverse trend with larger values of material parameter $K$. The effect of mixed convection parameter on temperature is shown in Fig.13. It is noticed that the temperature diminishes with enhancing the mixed convection parameter $\lambda$. The micro polar velocity and temperature have the similar behavior while the reverse trend the velocity distribution for the mixed convection parameter. Behavior of thermal relaxation parameter $\gamma$ on temperature distribution is shown in Fig.14. It can be seen that the fluid temperature and energy boundary layer diminished for larger values of thermal relaxation parameter $\gamma$.

This is due to reason that for larger thermal relaxation parameter the particles of the material require more opportunity to transfer heat to its adjacent particles. It is found that the heat transfers quickly throughout the objects for $\gamma=0$. Also, the temperature is lower for CattaneoChristov heat flux model when compared with Fourier's law. This situation coincides with the results of Hatat et al. [2016]. The physical behavior of variable thermal conductivity parameter $\varepsilon$ on temperature profiles is plotted in Fig.15. It can be seen from this figure that the temperature of the fluid increases with the higher values of variable thermal conductivity parameter $\mathcal{E}$. This is due to reason that as variable thermal conductivity parameter increased the thickness of the fluid temperature diminishes which contempt the temperature to increase. Fig.16 depicts the temperature profiles to the effect of Prandtl number. Both the thermal boundary layer thickness and temperature diminish to the enhancing values of Prandtl number ( $\mathrm{Pr}=0.5,0.7,1.0,2.0$ ). It is also seen that accumulation perception temperature is considerable larger at $\operatorname{Pr}=0.5$ when compared with $\operatorname{Pr}=2.0$. This is due to reason that thermal diffusivity increases for diminishing values of Pr. Influence of Eckert number $E c$ on temperature is reports in Fig.17. The temperature increases for larger values Eckert number. The increase in the buoyancy force due to an increase in the viscous dissipation parameter rise the temperature. Fig.18 is plotted for the influence of Biot number $\mathrm{Bi}$ on temperature profiles. Increasing values of Biot number boosts the dimensionless temperature. Because the Biot number contains the heat transfer coefficient and which enhances for larger values of Biot number.

The numerical in skin friction coefficient and Nusselt number for different values of dimensionless governing flow field physical parameters are displayed in Table 2. It is found that the magnitude of skin friction coefficient is boosts for higher values of material parameter, magnetic field parameter, Prandtl number and thermal relaxation parameter however the opposite results to mixed convection parameter, thermal conductivity parameter, Eckert number and Biot number. The hike in the values of magnetic field parameter, Prandtl number and thermal relaxation parameter enhances heat transfer rate while the reverse trend for material parameter, Eckert number and Biot number.

The validation of the present obtained results for $-\theta^{\prime}(0)$ by comparing with the earlier published works when $\operatorname{Pr}=1, \varepsilon=0, \gamma=0$ and $B i \rightarrow \infty$ is presented in Table 1 . We can found a nice agreement of the present results with the existed literature of Cortell (2007) and Waqas et al. (2016). This proves the validity of the present obtained results along with the accuracy of the numerical technique we used in this study.

Table1 Comparative of the present results for $-\theta^{\prime}(0)$ with the existing literature when $\operatorname{Pr}=1, \varepsilon=0, \gamma=0$ and $B i \rightarrow \infty$.

\begin{tabular}{|c|c|c|c|c|}
\hline$n$ & $E c$ & Waqas et al. (2016) & Cortell (2007) & Present results \\
\hline 0.5 & 0.0 & 0.595286 & 0.595277 & 0.5952 \\
\hline 1.5 & 0.0 & 0.574864 & 0.574537 & 0.5948 \\
\hline 0.5 & 0.1 & 0.556715 & 0.556623 & 0.5568 \\
\hline 1.5 & 0.1 & 0.531002 & 0.530966 & 0.5310 \\
\hline
\end{tabular}

Table 2 Numerical values of skin friction coefficient and Nusselt number for different physical flow parameters when $m_{0}=0.5$.

\begin{tabular}{|c|c|c|c|c|c|c|c|c|c|}
\hline$K$ & $M$ & $\lambda$ & $\varepsilon$ & $\operatorname{Pr}$ & $\gamma$ & $E c$ & $B i$ & $\operatorname{Re}_{x}^{1 / 2} C_{f}$ & $\operatorname{Re}_{x}^{-1 / 2} N u_{x}$ \\
\hline $\begin{array}{l}0.1 \\
0.5 \\
1.0\end{array}$ & $\begin{array}{l} \\
1.0 \\
2.0 \\
3.0\end{array}$ & 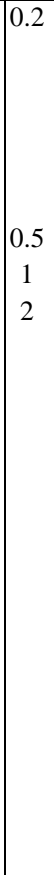 & $\begin{array}{c}0.5 \\
1 \\
2\end{array}$ & $\begin{array}{l}1 \\
2 \\
3\end{array}$ & $\mid \begin{array}{c}0.3 \\
0.5 \\
1\end{array}$ & $\begin{array}{c}0.1 \\
0.5 \\
1\end{array}$ & $\begin{array}{c}0.5 \\
1 \\
2\end{array}$ & $\begin{array}{c}-1.197653 \\
-1.306324 \\
-1.432000 \\
-1.481991 \\
-2.286251 \\
-3.203158 \\
-1.69451 \\
-1.24594 \\
-1.040779 \\
-1.96518 \\
-1.194466 \\
-1.189758 \\
-1.204168 \\
-1.200891 \\
-1.214544 \\
-1.99844 \\
-1.203845 \\
-1.212075 \\
-1.192537 \\
-1.170917 \\
-1.146044 \\
-1.179136 \\
-1.161394 \\
-1.144769\end{array}$ & $\begin{array}{c}0.169247 \\
0.170066 \\
0.170659 \\
0.166190 \\
0.155909 \\
0.1443660 \\
0.169733 \\
0.170175 \\
0.170896 \\
0.167840 \\
0.165077 \\
0.159171 \\
0.177488 \\
0.190089 \\
0.196528 \\
0.172221 \\
0.177620 \\
0.191302 \\
0.161701 \\
0.129030 \\
0.091447 \\
0.327393 \\
0.471396 \\
0.600466\end{array}$ \\
\hline
\end{tabular}




\section{CONCLUSIONS}

An analysis is reported to the impact of variable thermal conductivity and hydromagnetic on free convection flow of a micropolar fluid past a nonlinear stretched sheet with Cattaneo-Christov heat flux. The dimensionless governing equations are solved numerically using RungeKutta based shooting technique. The important key findings of the present study are:

1. Velocity and boundary layer thickness reduced with increasing values of $M$.

2. Effect of $\lambda$ is similar on micro-rotation velocity and temperature.

3. Both temperature and thermal boundary layer thickness decreases for enhancing values of Prandtl number.

4. An increase in variable thermal conductivity parameter $\varepsilon$ corresponds to lower temperature.

5. The enhancing values of thermal relaxation parameter $\gamma$ decrease the fluid temperature.

6. Heat transfer rate enhances for the thermal relaxation parameter $\gamma$ and Prandtl number Pr .

\section{ACKNOWLEDGMENT}

The authors wish to express their sincere thanks to reviewers for their precious suggestions and comments to improve the presentation of the manuscript.

\section{NOMENCLATURE}

\begin{tabular}{ll}
$B_{i}$ & Biot number \\
$C_{f}$ & local friction factor co-efficient \\
$C_{\rho}$ & specific heat at constant pressure \\
$E c$ & Eckert number \\
$G r_{x}$ & thermal buoyancy parameter \\
$g$ & Gravitational acceleration \\
$h_{f}$ & convective heat transfer coefficient \\
$j$ & Micro inertia \\
$K$ & micropolar parameter \\
$\kappa$ & vortex viscosity \\
$k(T)$ & variable thermal conductivity \\
$k_{\infty}$ & thermal conductivity of ambient fluid \\
$M$ & Hartman number \\
$m_{0}$ & boundary parameter \\
$N$ & micro-rotation velocity \\
$N u_{x}$ & Nusselt number \\
$\mathrm{Pr}$ & Prandtl number \\
$q_{w}$ & surface heat flux \\
$\mathrm{Re}_{x}$ & local Reynolds number \\
$T$ & temperature of the fluid \\
$T_{f}$ & convective fluid temperature \\
$T_{w}$ & stretching sheet temperature \\
$T_{\infty}$ & temperature far away from the stretching sheet \\
$u$ & velocity of the fluid along the $x$ - axis \\
$\rho$ & velocity of the fluid along the $y$ - axis \\
$\mu$ & fluid density \\
& dynamic viscosity \\
\hline &
\end{tabular}

$\begin{array}{ll}\beta & \text { thermal expansion coefficient } \\ v & \text { kinematic viscosity } \\ \gamma^{*} & \text { spin gradient viscosity } \\ \alpha & \text { thermal diffusivity } \\ \varepsilon & \text { small scale parameter } \\ \lambda & \text { mixed convection parameter or buoyancy parameter } \\ \gamma & \text { thermal relaxation parameter } \\ \tau_{w} & \text { surface shear stress }\end{array}$

\section{REFERENCES}

Eringen, AC., 1966, Theory of Micro Polar Fluids, J. Math. Mech.; 16, $1-18$.

Peddieson, J., McNitt, RP., 1970, "Boundary-Layer Theory For a Micro Polar Fluid,” Recent Adv. Eng. Sci, 5, 405-426

http://dx.doi.org/10.1016/j.jppr.2016.11.005

Hassanien, IA., Gorla, RSR., 1990, "Heat Transfer to a Micro Polar Fluid From a Non-Isothermal Stretching Sheet with Suction and Blowing,” Acta Mech, 84,191-199. http:// doi:10.1007/BF01176097

Gorla, R.S.R., 1995, "Unsteady Mixed Convection in MicroPolar Boundary Layer Flow on a Vertical Plate," Fluid Dynamics Research, 15(4), 237-250.

Hady, FM., 1996, "Short Communication on the Solution of Heat Transfer to Micro Polar Fluid from a Non-Isothermal Stretching Sheet with Injection,” Int. J. Num. Meth. Heat Fluid Flow, 6, 99-104.

http://dx.doi.org/10.1016/j.joems.2011.12.009

Ishak, A., Nazar, R., Pop, I., 2006, "Moving Wedge and Flat Plate in a Micro Polar Fluid,” Int. J. Eng. Sci, 44, 1225-1236.

http://dx.doi.org/10.1016/j.ijengsci.2006.08.005

Ishak, A., Nazar, R., Pop, I., 2008, 'Heat Transfer over a Stretching Surface with Variable Surface Heat Flux in Micro Polar Fluids," Phys. Lett. A, 372, 559-561.

http://dx.doi.org/10.1063/1.4938551

Hayat, T., Abbas, Z., Javed, T., 2008, "Mixed Convection Flow of a Micro Polar Fluid over a Non-Linear Stretching Sheet," Phys. Lett. A, 372, 637-647.

Sajid, M., Abbas, Z., Hayat, T., 2009, "Homotopy Analysis for Boundary Layer Flow of a Micro Polar Fluid through a Porous Channel,” Appl. Math. Model, 33, 4120-4125.

http://dx.doi.org/10.1016/j.apm.2009.02.006

Ashraf, M., Batool, K., 2013, "MHD Flow and Heat Transfer of a Micro Polar Fluid over a Stretchable Disk,” J. Theor. Appl. Mech, 51 (1), 2538

Mahmud, M.A.A., Waheed, SE., 2012, “MHD Flow and Heat Transfer of a Micro Polar Fluid over a Stretching Surface with Heat Generation (Absorption) and Slip Velocity,” J Egypt Math Soc, 12, 20-27. http://dx.doi.org/10.1016/j.joems.2011.12.009

Gnaneswara Reddy, M., 2013, "Heat Generation and Radiation Effects on Steady MHD Free Convection Flow of Micro Polar Fluid Past a Moving Surface," Journal of Computational and Applied Research in Mechanical Engineering, 2 (2), 1-10. 
El-Aziz, M.A., 2013, "Mixed Convection Flow of a Micropolar Fluid From an Unsteady Stretching Surface with Viscous Dissipation,” J. Egypt. Math. Soc, 21, 385-394.

http://dx.doi.org/10.1016/j.joems.2013.02.010

Gnaneswara Reddy, M., Venugopal Reddy, K., 2015, “Influence of Joule Heating on MHD Peristaltic Flow of a Nanofluid with Compliant Walls,” Procedia Engineering, 127, 1002 - 1009.

http://dx.doi.org/10.1016/j.proeng.2015.11.449

Mehmood ,R., Nadeem, S., Masood, S., 2016, "Effects of Transverse Magnetic Field on a Rotating Micropolar Fluid Between Parallel Plates with Heat Transfer,” J. Magn.Magn. Mater, 401, 1006-1014. http://dx.doi.org/10.1016/j.jmmm.2015.10.102

Gnaneswara Reddy, M., 2014,“Effects of Thermophoresis, Viscous Dissipation and Joule Heating on Steady MHD Flow over an Inclined Radiative Isothermal Permeable Surface with Variable Thermal Conductivity,” Journal of Applied Fluid Mechanics, 7 (1), 51-61

Gnaneswara Reddy, M., 2014, “Influence of Thermal Radiation, Viscous Dissipation and Hall Current on MHD Convection Flow over a Stretched Vertical Flat Plate,” Ain Shams Engineering Journal, 5, 169175.

http://dx.doi.org/10.1016/j.asej.2013.08.003

Alam, MdS., Khan, MAH., Alim,MA., 2016 ,“Irreversibility Analysis of Variable Thermal Conductivity MHD Radiative Flow In Porous Channel with Different Nanoparticles,” Journal of Porous Media,19 (5), 423-439.

Gnaneswara Reddy, M., Makinde, OD., 2016, "Magneto Hydrodynamic Peristaltic Transport of Jeffrey Nanofluid in an Asymmetric Channel,” Journal of Molecular Liquids, 223, 1242-1248.

http://dx.doi.org/10.1016/j.molliq.2016.09.080

Sandeep, N.,and Gnaneswara Reddy,M., 2017, “Heat Transfer of Nonlinear Radiative Magneto Hydrodynamic Cu-Water Nanofluid Flow over Two Different Geometries,” Journal of Molecular Liquids ,225, 87-94.

http://dx.doi.org/10.1016/j.molliq.2016.11.026

Fourier, JBJ., 1822, Theorie Analytique De La Chaleur, Paris.

Cattaneo,C., 1948, Sulla conduzione del calore, Atti Semin Mat. Fis. Univ. Modena Reggio Emilia. 3: 83-101.

http://dx.doi.org/10.1063/1.4929523
Christov, CI., 2009, “On Frame Indifferent Formulation of The Maxwell-Cattaneo Model of Finite Speed Heat Conduction,” Mech. Res. Commun, 36, 481-486.

http://dx.doi.org/10.1371/journal.pone.0153481

Straughan, B., 2010 "Thermal Convection with the Cattaneo-Christov Model,” Int. J. Heat Mass Transf, 53, 95-98.

http://dx.doi.org/10.1016/j.ijheatmasstransfer.2009.10.001

Tibullo, V., Zampoli, V., 2011, “A Uniqueness Result for the CattaneoChristov Heat Conduction Model Applied to Incompressible Fluids," Mech.Res.Commun,38,77-99.

http://dx.doi.org/10.1016/j.mechrescom.2010.10.008

Han, S., Zheng, L., Li, C., Zhang, X., 2014, “Coupled Flow and Heat Transfer in Viscoelastic Fluid with Cattaneo-Christov Heat Flux Model,” Appl. Math. Lett, 38, 87-93

http://dx.doi.org/10.1371/journal.pone.0137363

Mustafa, M., 2015, “Cattaneo-Christov Heat Flux Model For Rotating Flow and Heat Transfer of Upper-Convicted Maxwell Fluid,” AIP Adv., 5, 047109.

http://dx.doi.org/10.1063/1.4917306

Ahmad Khan, J., Mustafa, M., Hayat, T., Alsaedi, A., 2015, “Numerical Study of Cattaneo-Christov Heat Flux Model For Viscoelastic Flow Due To an Exponentially Stretching Surface,” PLoS ONE.

http://dx.doi.org/10.1371/journal.pone.0137363

Hayat, T., Khan, MI., Farooq, M., Alsaedi, A., Waqas, M., Yasmeen, T., 2016 "Impact of Cattaneo-Christov Heat Flux Model In Flow of Variable Thermal Conductivity Fluid over a Variable Thicked Surface,” Int. J. Heat Mass Transf, 99, 702-710.

http://dx.doi.org/10.1063/1.4929523

Waqas, M., Farooq, M., Khan, M., Alsaedi, A., Hayat, T., Yasmeen, T., 2016, "Magneto Hydrodynamic (MHD) Mixed Convection Flow of Micro Polar Liquid Due to Nonlinear Stretched Sheet with Convective Condition,” International Journal of Heat and Mass Transfer, 102,766772.

http://dx.doi.org/10.1016/j.ijheatmasstransfer.2016.05.142

Cortell, R., 2007, "Viscous Flow and Heat Transfer over a Nonlinearly Stretching Sheet,” Appl. Math. Comput, 184, 864-873. 